\title{
On the Use of Multidimensional Data Analysis Techniques for Corporate Valuation
}

\author{
Georgeta Vintilă $\check{1}^{1}$ Ştefan Cristian Gherghina ${ }^{1}$ \\ ${ }^{1}$ Department of Finance, Bucharest University of Economic Studies, Bucharest, Romania \\ Correspondence: Ştefan Cristian Gherghina, Bucharest University of Economic Studies, 6 Romana Square, \\ district 1, 010374, Bucharest, Romania. Tel: 40-21-319-1900. E-mail: stefan.gherghina@fin.ase.ro
}

Received: March 12, 2014

Accepted: April 4, $2014 \quad$ Online Published: May 5, 2014

doi:10.5539/mas.v8n3p202

URL: http://dx.doi.org/10.5539/mas.v8n3p202

\begin{abstract}
The aim of this research consists in the investigation of a random sample of companies which belong to five European emerging countries, respectively Hungary, Poland, Russia, Slovakia, and Ukraine, from the valuation perspective, by using multidimensional data analysis techniques. Thus, by employing the principal component analysis, after transforming the initial characteristics there resulted two principal components, also considering the restriction of minimizing the loss of information. Subsequently, by the instrumentality of factor analysis, there resulted two factors required to explain the correlations existing between variables. The usefulness of both multidimensional data analysis techniques emerges from the reduction of the significant number of variables in a lesser number of principal components, respectively factors.
\end{abstract}

Keywords: principal component analysis, factor analysis, eigenvalues, eigenvectors, firm value

\section{Introduction}

Often, in order to establish the value of a given company we could own an exhaustive set of indicators from financial statements or which could be computed based on financial reports. However, the significant dimensionality of the employed measures with the purpose previously mentioned, frequently conduct to the impairment of the valuation process. On the other hand, the availability of more indicators in order to reflect firm value could support contradictory results. Besides, the task of the valuator could be more facile if the indicators used would be reduced to some components as linear combinations of the original variables. Thus, applying the principal component analysis could represent a proper technique in order to facilitate the evaluation process. Likewise, by employing the factor analysis we will identify the essential factors through which we could explain the interdependencies existing between the indicator variables represented by the valuation ratios. This paper aims at exploring a random sample of companies which belong to five European emerging countries, respectively Hungary, Poland, Russia, Slovakia, and Ukraine, in order to determine their value, by using the aforementioned multidimensional data analysis techniques. The novelty of current research consists in using SAS 9.2 by the valuators in order to establish the value of the companies. SAS (Statistical Analysis System)is a software suite which began at North Carolina State University as a project to analyze agricultural research. Since demand for such software grew, SAS was founded in 1976 to help all sorts of customers, from pharmaceutical companies and banks to academic and governmental entities. The utility of current paper consists inthe reduction of the significant number of variables in a lesser number of principal components, respectively factors.

The rest of this paper proceeds as follows. In Section 2 we emphasize the numerous important applications of multidimensional data analysis techniques, while Section 3 describes the data and the research methodology, as well as the fundamentals of principal component analysis and factor analysis. The results of the empirical research are presented in Section 4, while Section 5 concludes the paper.

\section{The Applications of Multidimensional Data Analysis Techniques}

Principal component analysis (hereafter PCA) technique was developed by Pearson (1901), having a great usefulness in the exploratory data analysis and in the achievement of the prediction models. Depending on the field of application, this multidimensional data analysis technique is also named the discrete Karhunen-Loève transform (KLT), the Hotelling transform, or the proper orthogonal decomposition (POD). In fact, there are many fields such as ecology, chemometrics, or economy, where multivariate analyses are employed in order to 
describe and summarize large data sets by removing any redundancy existing in the data (Dray, 2008; Zou, Hastie \& Tibshirani, 2006). Likewise, PCA is the most popular multivariate statistical technique used by almost all scientific disciplines (Abdi \& Williams, 2010) and the simplest multivariate method (Jackson, 1993). Thereby, we acknowledge numerous important applications such as human face recognition (Hancock, Burton \& Bruce, 1996) or handwritten zip code classification (Hastie, Tibshirani \& Friedman, 2009). We emphasize that PCA was employed on facial images and bounded these to human performance on recognition of own and other-race facial images (O'Toole, Deffenbacher, Valentin \& Abdi, 1994). Withal, PCA was used in gene expression data analysis (Alter, Brown \& Botstein, 2000). Subsequently, the gene shaving method was employed to analyze gene expression measurements based on samples from patients with diffuse large B-cell lymphoma (Hastie et al., 2000). Thus, the gene shaving technique using PCA identified a small cluster of genes whose expression was highly predictive of survival. In the financial field, PCA is widely used thanks to its multiple applications. Thus, this technique was employed in order to estimate the bankruptcy risk (Altman, 1968; Conan \& Holder, 1979). Further, bankruptcy prediction models recorded a broader usage. Also, Meric, Leal, Ratner, \& Meric (2001) examined the possibilities of international portfolio diversification through investment in the principal capital markets from Latin America. Leger and Leone (2008) analysed the economic variables which could help to explain the principal components in UK stock returns.

Factor analysis (hereafter FA) was introduced by the American psychologist Thurstone (1931). Accordingly, exploratory factor analysis (EFA) is an important tool for organizational researchers (Conway \& Huffcutt, 2003). Thus, Ford, MacCallum and Tait (1986) investigated the application of EFA as regards 152 studies published in the Journal of Applied Psychology, Personnel Psychology, and Organizational Behavior and Human Performance, over the period 1975-1984. The results showed the fact that the components model was the most popular factor model employed ( $\mathrm{N}=64 ; 42.1$ percent), in contrast to common factor model ( $\mathrm{N}=52 ; 34.2$ percent), whereas in 36 papers (23.7 percent) was impossible to determine which factor model was used. As well, Fabrigar, Wegener, MacCallum and Strahan (1999) reported for Journal of Applied Psychology, over the period 1991-1995, that PCA was used in 48.3 percent of the cases in contrast to common factors (22.4 percent), whilst in 25.9 percent of the cases the factor extraction model was unknown. Park, Dailey, \& Lemus (2002) reviewed the articles published in three major communication journals: Human Communication Research, Communication Monographs, and Communications Research, from 1990 to 2000, and found an usage of principal component analysis in 52.94 percent of cases, common factors in 11.76 percent of papers, while 31.93 percent did not specify the type of analysis. As regards financial investigations, since the research of FA pioneers (Pinches, Mingo,\& Caruthers, 1972) which tried to realize a classification of financial ratios related to US industrial firms, FA is used as a way in order to remove the redundancy and to reduce the number of financial ratios required for empirical researches. Therefore, Ali and Charbaji (1994) used this technique within the international commercial airlines sector to reduce 42 financial ratios to five underlying factors. Tan, Koh and Low (1997) applied FA for the companies listed on the Stock Exchange of Singapore, thus reducing 29 financial ratios to eight underlying factors. De, Bandyopadhyay and Chakraborty (2011) employed FA for a set of 44 financial ratios corresponding to a sample of companies from the Indian iron and steel industry and derived eight underlying factors.

Thus, compared with previous studies, our paper employs multidimensional data analysis techniques in order to determine the value of a random sample of companies out of European emerging countries. Firm value is very important for individual investors since it reflects the underlying value of their stake in an enterprise. As the estimated value is more accurate, the investors could take the proper investment decisions, respectively to sell, to buy, or to maintain their holdings.

\section{Data and Research Methodology}

The aim of this research consists in the valuation of a random sample of companies which belong to five European emerging countries. Thus, the randomly selected sample comprises 310 companies as follows: 11 companies from Hungary, 125 companies from Poland, 89 companies from Russia, 5 companies from Slovakia, and 80 companies from Ukraine. Thereby, in order to evaluate the selected companies we will use ten financial ratios which were computed based on the data from financial statements of the companies, the values corresponding to 2009. The indicators employed and their computation method will be described below. The financial statement data was provided by ISI Emerging Markets. We will use the software instrument SAS 9.2 in order to apply the multidimensional data analysis techniques. We will employ the PRINCOMP procedure in order to perform principal component analysis, as well PROC FACTOR statement towards factor analysis (Delwiche \& Slaughter, 2008; Fernandez, 2010). 
I1: $\mathbf{D E}=$ the debt to equity ratio, calculated through dividing total liabilities by stockholders' equity. Also known as global financial autonomy, this indicator assesses the size of external funds compared with the funds from shareholders;

I2: DTA = the debt to total assets ratio. Also known as the general indebtednessratio, this indicator reflects the means in which the company's assets are financed by debt;

I3: $\mathbf{L E V}=$ the financial debt to equity ratio signifies financial leverage ratio, through which is reflected the financial managers' ability to collect outside resources in order to stimulate the equity' efficiency;

I4: EPS = earnings per share or the internal return of a certain share in terms of the income which is generated by that share in a financial year, is computed through dividing net income by total number of capital stock shares. This ratio allows the investors to compare the results recorded by the company in order to decide if the owned capital stock shares will be kept, cleared, or raised;

I5: $\mathbf{P E R}=$ price/earnings ratio, computed by dividing the company's current share price by its per-share earnings, is showing the market return of a certain share in terms of the amount which the investors are willing to pay per dollar of company's earnings. Also, this ratio shows the period required to a shareholder in order to recover the invested capital;

I6: $\mathbf{R O S}=$ return on sales is the ratio of net income before interest and tax divided by net sales, usually reported in percentage. On the one hand, ROS highlights the part of each dollar of sales that the company is able to turn into income. On the other hand, ROS shows the contribution of company's income in order to strengthen the self-financing ability;

I7: $\mathbf{C R}=$ current ratio is the ratio of current assets recorded in the balance sheet of a particular company for a given period of time divided by its current liabilities (short-term liabilities). This indicator reflects the possibility of current patrimonial elements to transform into liquidity in a short time in order to pay the current liabilities;

I8: $\mathbf{Q R}=$ quick ratio, also known the Acid-test ratio is calculated as the difference between current assets and inventory, divided by current liabilities. This indicator reflects the possibility of current assets represented by accounts receivable and short-term investments to cover the current liabilities;

19: ROA = return on assets is computed by dividing the company's income after interest and tax by its total assets. This indicator shows the efficiency recorded in company's assets utilization;

I10: ROE = return on equity is equal to net income divided by shareholders' equity. The contribution of shareholders in order to finance the company is measured through shareholders' equity, thus return on equity reflecting the efficiency of the company at generating profits from every unit of shareholders' equity.

\subsection{Principal Component Analysis Description}

By employing the multidimensional data analysis technique entitled principal component analysis, there will result the decomposition of total variability from the initial causal space through a reduced number of components. However, this decomposition will not contain informational redundancy. Thus, it is followed a collapse of the variables to a reduced number of composite variables. By the instrumentality of PCA our purpose is to synthesize the distinctions amongst the 310 selected companies, existing at the ten researched factors, through a reduced number of components which are uncorrelated.

The principal components are abstract vector variables defined as linear combinations of the original variables, characterized by the following two fundamental properties: the principal components are uncorrelated two by two, and the sum of squares of the coefficients which define the linear combination corresponding to a principal component is equal to one. Peres-Neto, Jackson and Somers (2005) noticed that detecting certain relationships by generating linear combinations of variables showing common trends of variation exhibit a significant scientific contribution as regards the recognition of patterns in the data. Thus, the first principal component is a linear normalized combination whose variance is maximum. The second principal component is an uncorrelated linear combination with the first principal component, whose variance is as high as possible, but lesser than the variance of the first principal component. The initial causal space subject to our research is figured by ten explanatory variables $x_{1}, x_{2}, \ldots, x_{9}, x_{10}$, thus signifying the fact that each of the 310 companies is evaluated by ten financial indicators, as defined previously.

The principal components corresponding to the researched causal space are described through a vector with ten dimensions, labeled with w: 


$$
\mathrm{w}=\left(\begin{array}{c}
\mathrm{w}_{1} \\
\mathrm{w}_{2} \\
\cdots \\
\mathrm{w}_{9} \\
\mathrm{w}_{10}
\end{array}\right)
$$

Each coordinate $w_{i}$ of this vector represents a principal component defined compared with the original variables through the following linear combination:

$$
\mathrm{w}_{\mathrm{i}}=\alpha_{1}^{(\mathrm{i})} * \mathrm{x}_{1}+\alpha_{2}^{(\mathrm{i})} *_{\mathrm{x}_{2}}+\ldots+\alpha_{9}^{(\mathrm{i})} * \mathrm{x}_{9}+\alpha_{10}^{(\mathrm{i})} * \mathrm{x}_{10} \quad \mathrm{i}=1,2, \ldots, 9,10
$$

The coefficients $\alpha_{j}^{(i)}$ are the coordinates of the eigenvectors corresponding to the covariance matrix of the original variables $\mathrm{x}_{1}, \mathrm{x}_{2}, \ldots, \mathrm{x}_{9}, \mathrm{x}_{10}$, while the principal components' variances are the eigenvalues of this matrix.

Thereby, it is followed to solve the following extreme problem. Depending on the type of the function $\phi$, the optimum criterion could be maximum or minimum.

$$
\left\{\begin{array}{l}
\text { Opt } \phi(\mathrm{x}, \mathrm{w}) \\
\mathrm{w}=\mathrm{A}^{\mathrm{T}} * \mathrm{x}
\end{array}\right.
$$

We will consider the fact that the vectors $\alpha^{(\mathrm{i})}$ are the columns of matrix A of dimensions $10 \times 10$, having the following form:

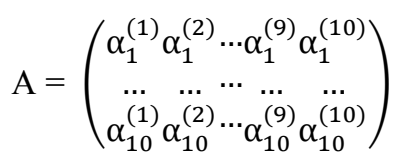

Besides, we will suppose the fact that $\mathrm{x}$ is the vector whose coordinates are the original variables $\mathrm{x}_{1}, \mathrm{x}_{2}, \ldots, \mathrm{x}_{9}$, $\mathrm{x}_{10}$, whereas $\mathrm{w}$ is the vector whose coordinates are the principal components $\mathrm{w}_{1}, \mathrm{w}_{2}, \ldots, \mathrm{w}_{9}, \mathrm{w}_{10}$.

Thus, the linear combinations which define the principal components could be represented as below:

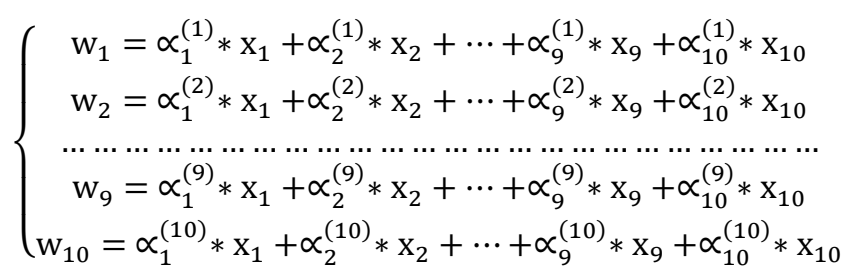

Under matrix form, the linear combinations related to the principal components could be represented as follows:

$$
\left(\begin{array}{c}
\mathrm{w}_{1} \\
\mathrm{w}_{2} \\
\cdots \\
\mathrm{w}_{9} \\
\mathrm{w}_{10}
\end{array}\right)=\left(\begin{array}{ccccc}
\alpha_{1}^{(1)} & \alpha_{2}^{(1)} & \cdots & \alpha_{9}^{(1)} & \alpha_{10}^{(1)} \\
\alpha_{1}^{(2)} & \alpha_{2}^{(2)} & \cdots & \alpha_{9}^{(2)} & \alpha_{10}^{(2)} \\
\cdots & \cdots & \cdots & \cdots & \cdots \\
\alpha_{1}^{(2)} & \alpha_{2}^{(2)} & \cdots & \alpha_{9}^{(2)} & \alpha_{10}^{(2)} \\
\alpha_{1}^{(10)} & \alpha_{2}^{(10)} & \cdots & \alpha_{9}^{(10)} & \alpha_{10}^{(10)}
\end{array}\right) *\left(\begin{array}{c}
\mathrm{x}_{1} \\
\mathrm{x}_{2} \\
\cdots \\
\mathrm{x}_{9} \\
\mathrm{x}_{10}
\end{array}\right)
$$

The mathematical model of principal component analysis is defined as follows:

$$
\left\{\begin{array}{l}
\max \operatorname{Var}(\mathrm{w}) \\
\mathrm{w}=\mathrm{A}^{\mathrm{T}} * \mathrm{x}
\end{array}\right.
$$

\subsection{Factor Analysis Description}

The multidimensional data analysis technique entitled factor analysis is employed in order to explain the correlations between several variables named indicators, by the instrumentality of a lower number of sorted and uncorellated factors, named common factors. However, the common factor represents a fundamental concept within factor analysis which could be considered as a random variable with a certain probability distribution. Likewise, with the aim of numerical valuations' achievement we distinguish the variable entitled indicator, whose observations are known as scores. Additionally, the indicators have associated unique factors. The unique factor is exerting the influence in a one-sided manner on a single indicator (measured) variable. Besides, the unique factor could not be subject to a direct observation and measurement process. Outside the influence exerted by the common factor and by the unique factor, we distinguish in addition the influence of the measurement errors, considered negligible. 
The factor model has the following mathematical form, considering the fact that the measured variables are marked with $x_{j}$, the common factors are marked with $f_{j}$, the unique factors are marked with $u_{j}$, while $a_{i j}$ represents the intensity of the common factor $f_{j}$ compared with the measured variable $x_{j}$ :

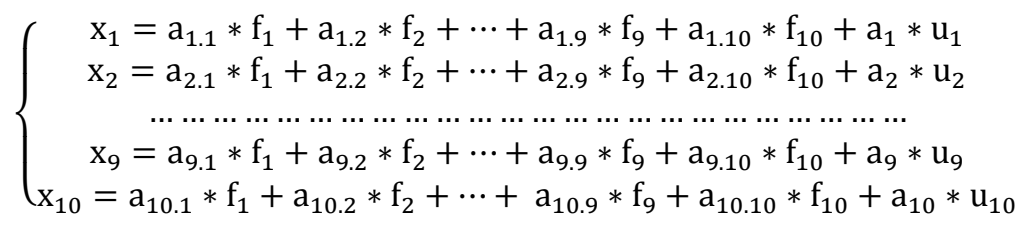

Under matrix form, the factor model has the following representation:

$$
\begin{gathered}
\mathrm{x}=\mathrm{F} * \mathrm{f}+\mathrm{D} * \mathrm{u} \\
\left(\begin{array}{c}
\mathrm{x}_{1} \\
\mathrm{x}_{2} \\
\cdots \\
\mathrm{x}_{9} \\
\mathrm{x}_{10}
\end{array}\right)=\left(\begin{array}{ccc}
\mathrm{a}_{1.1} & \cdots & \mathrm{a}_{1.10} \\
\mathrm{a}_{2.1} & \cdots & \mathrm{a}_{2.10} \\
\ldots & \cdots & \cdots \\
\mathrm{a}_{9.1} & \cdots & \mathrm{a}_{9.10} \\
\mathrm{a}_{10.1} & \cdots & \mathrm{a}_{10.10}
\end{array}\right) *\left(\begin{array}{c}
\mathrm{f}_{1} \\
\mathrm{f}_{2} \\
\cdots \\
\mathrm{f}_{9} \\
\mathrm{f}_{10}
\end{array}\right)+\left(\begin{array}{ccc}
\mathrm{a}_{1} & \cdots & 0 \\
0 & \cdots & 0 \\
\ldots & \cdots & \ldots \\
0 & \cdots & 0 \\
0 & \cdots & a_{10}
\end{array}\right) *\left(\begin{array}{c}
\mathrm{u}_{1} \\
\mathrm{u}_{2} \\
\cdots \\
\mathrm{u}_{9} \\
\mathrm{u}_{10}
\end{array}\right)
\end{gathered}
$$

However, unlike principal component analysis in the context of which the variability that characterizes the initial causal space is undifferentiated considered, in factor analysis, the variability of the initial causal space is considered as a composition of variances which are constituted under the influence of the factors previously mentioned. The variance $\sigma_{\mathrm{j}}^{2}$ related to the variable $\mathrm{x}_{\mathrm{j}}$ could be shared in three important components: the communality $\mathrm{h}_{\mathrm{j}}^{2}$ (that part of the total variance $\sigma_{\mathrm{j}}^{2}$ that explains the information which is common to all the variables which define the causal space and which are forming under the influence of common factors), the uniqueness $a_{j}^{2}$ (that part of the total variance $\sigma_{j}^{2}$ that expresses significant information of specific type which characterizes the particular variable $\mathrm{x}_{\mathrm{j}}$ and which is constituted under the influence of the unique factor), and the residuality $\mathrm{e}_{j}^{2}$ (that part of the total variance $\sigma_{j}^{2}$ which is formed under the influence of the residual factor that is associated with the considered variable and which shows insignificant information with specific feature related to the variable $\mathrm{x}_{\mathrm{j}}$ ).

\section{Empirical Research Results}

\subsection{The Results of the Principal Component Analysis}

The script related to the principal component analysis employed in SAS 9.2 is showed in Apendix . The covariance matrix of the original variables is presented in Table 1. However, the covariance matrix is very important within current empirical research due to the principal components' properties. The total variance recorded is $\mathbf{2 6 . 4 2 5 7}$.

Table 1. Covariance matrix

\begin{tabular}{lcccccccccc}
\hline Variable & DE & DTA & LEV & EPS & PER & ROS & CR & QR & ROA & ROE \\
\hline DE & 14.7157 & 0.3548 & 2.2354 & -0.0288 & -0.3265 & -0.0118 & -0.4418 & -0.2174 & -0.0529 & -0.8544 \\
DTA & 0.3548 & 0.0628 & 0.1268 & -0.0019 & -0.0305 & 0.0028 & -0.1907 & -0.1579 & -0.0085 & -0.0190 \\
LEV & 2.2354 & 0.1268 & 3.6779 & -0.0025 & -0.0270 & 0.0712 & -0.3715 & -0.3432 & -0.0018 & -0.0614 \\
EPS & -0.0288 & -0.0019 & -0.0025 & 0.0041 & 0.0016 & 0.0055 & -0.0051 & -0.0037 & 0.0024 & 0.0051 \\
PER & -0.3265 & -0.0305 & -0.0270 & 0.0016 & 0.7399 & 0.1380 & 0.0065 & -0.0051 & 0.0041 & 0.0189 \\
ROS & -0.0118 & 0.0028 & 0.0712 & 0.0055 & 0.1380 & 0.9886 & 0.0057 & -0.0112 & 0.0262 & 0.0515 \\
CR & -0.4418 & -0.1907 & -0.3715 & -0.0051 & 0.0065 & 0.0057 & 3.4419 & 2.8056 & 0.0327 & 0.0745 \\
QR & -0.2175 & -0.1579 & -0.3432 & -0.0037 & -0.0051 & -0.0112 & 2.8056 & 2.5909 & 0.0249 & 0.0501 \\
ROA & -0.0529 & -0.0085 & -0.0018 & 0.0024 & 0.0041 & 0.0262 & 0.0327 & 0.0249 & 0.0102 & 0.0227 \\
ROE & -0.8544 & -0.0190 & -0.0614 & 0.0051 & 0.0189 & 0.0515 & 0.0745 & 0.0501 & 0.0227 & 0.1938 \\
\hline
\end{tabular}

The principal components are sorted in Table 2 in a descending order of the retained information as percentage from the total variance. The column entitled Proportion highlights the percentage out of the initial information of each variable from the ten selected variables, which is synthesized in the extracted principal components. 
Thereby, the first principal component explains about 57.72 percent out of the total variance, the second principal component explains about 22.29 percent out of the total variance, the third principal component explains about 12.06 percent out of the total variance, while the fourth principal component explains about 3.97 percent out of the total variance. As well, the first four principal components record eigenvalues greater than one, values which could be noticed in the Eigenvalue column. However, the first four principal components cumulate 96.05 percent out of total information, fact presented in the Cumulative column. Thus, if it is added a new principal component there would result 98.60 percent out of total information.

Table 2. Eigenvalues of the covariance matrix

\begin{tabular}{lcccc}
\hline & Eigenvalue & Difference & Proportion & Cumulative \\
\hline $\mathbf{1}$ & 15.2523 & 9.3610 & 0.5772 & 0.5772 \\
$\mathbf{2}$ & 5.8914 & 2.7033 & 0.2229 & 0.8001 \\
$\mathbf{3}$ & 3.1881 & 2.1393 & 0.1206 & 0.9208 \\
$\mathbf{4}$ & 1.0488 & 0.3748 & 0.0397 & 0.9605 \\
$\mathbf{5}$ & 0.6740 & 0.4968 & 0.0255 & 0.9860 \\
$\mathbf{6}$ & 0.1772 & 0.0366 & 0.0067 & 0.9927 \\
$\mathbf{7}$ & 0.1406 & 0.0968 & 0.0053 & 0.9980 \\
$\mathbf{8}$ & 0.0438 & 0.0373 & 0.0017 & 0.9996 \\
$\mathbf{9}$ & 0.0065 & 0.0036 & 0.0002 & 0.9999 \\
$\mathbf{1 0}$ & 0.0030 & & 0.0001 & 1.0000 \\
\hline
\end{tabular}

The both of graphs showed in Figure 1, proposed by Cattell (1966), are used in order to establish the number of principal components. Thus, in the first graph is remarked that after the second point which symbolizes the second principal component, the slope decreases. However, we could retain two principal components.

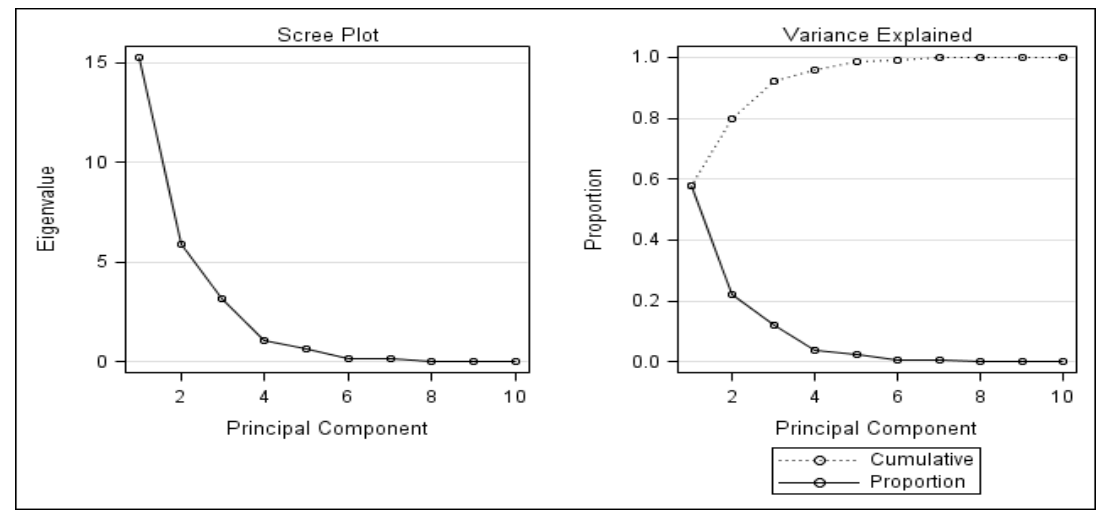

Figure 1. Eigenvalue plot

The number of principal components which are retained in the analysis is determined based on a cut in the graph parallel with the ordinate. Thereby, the number of principal components is the first number from the left of the cut so the part of the graph from the right of the cut have a slope equal to zero. In the graph from the left side each point represents an eigenvalue, while in the graph from the right side each point represents the proportion (cumulative) out of the variance explained by each component. However, in order to express the ten variables there could be satisfactory only a single principal component, but this could not adequately cover the variability from the space of the ten variables because the proportion is only 57.72 percent. Thus, based on the slope criterion, there will be retained two principal components. Likewise, by considering the covering criterion, the first two principal components ensure a cover of 80.01 percent out of the variability from the space of the ten variables. On the other hand, according to the Kaiser criterion there should be retained only the eigenvalues greater than one. However, within current empirical research we could not employ the Kaiser criterion because 
data standardization was not employed. We notice the fact that the data was not standardized because there were not recorded high standard deviation of the variables. The standard deviation of the ten variables employed in this analysis in order to evaluate the companies is presented in Table 3.

Table 3. Standard deviation of the variables

\begin{tabular}{|c|c|c|c|c|c|c|c|c|c|c|}
\hline & DE & DTA & LEV & EPS & PER & ROS & CR & QR & ROA & ROE \\
\hline StD & 3.8361 & 0.2506 & 1.9178 & 0.0639 & 0.8602 & 0.9943 & 1.8552 & 1.6096 & 0.1009 & 0.4402 \\
\hline
\end{tabular}

The eigenvectors of the covariance matrix are presented in Table 4. The importance of the eingenvectors is emphasized by the fact that they provide the coefficients of the original variables out of the linear equations related to the principal components. We underline that the technique of PCA represents a multidimensional method of analysis which has the aim of determining new variables entitled principal components expressed as linear combinations of the original variables. Thereby, these new resulted variables are characterized by a maximum variability.

Table 4. Eigenvectors of the covariance matrix

\begin{tabular}{lcccccccccc}
\hline Variable & Prin1 & Prin2 & Prin3 & Prin4 & Prin5 & Prin6 & Prin7 & Prin8 & Prin9 & Prin10 \\
\hline DE & 0.9772 & 0.0897 & -0.1788 & 0.0195 & 0.0188 & -0.0138 & 0.0606 & -0.0194 & -0.0069 & 0.0035 \\
DTA & 0.0255 & -0.0394 & 0.0067 & -0.0077 & -0.0347 & 0.0165 & 0.0191 & 0.9834 & 0.1644 & -0.0419 \\
LEV & 0.1920 & -0.1369 & 0.9706 & -0.0365 & 0.0044 & 0.0124 & -0.0219 & -0.0166 & -0.0021 & 0.0005 \\
EPS & -0.0019 & -0.0014 & 0.0007 & 0.0053 & -0.0021 & 0.0037 & 0.0251 & -0.0457 & 0.4915 & 0.8693 \\
PER & -0.0225 & -0.0045 & 0.0154 & 0.3960 & 0.9170 & 0.0057 & 0.0164 & 0.0345 & 0.0049 & -0.0017 \\
ROS & -0.0003 & -0.0029 & 0.0341 & 0.9156 & -0.3948 & 0.0167 & -0.0633 & -0.0026 & -0.0197 & 0.0061 \\
CR & -0.0514 & 0.7459 & 0.1236 & 0.0067 & 0.0007 & -0.6493 & -0.0470 & 0.0423 & 0.0011 & 0.0067 \\
QR & -0.0339 & 0.6444 & 0.0885 & -0.0123 & 0.0004 & 0.7578 & 0.0357 & 0.0119 & 0.0030 & -0.0043 \\
ROA & -0.0037 & 0.0062 & 0.0049 & 0.0248 & -0.0123 & -0.0152 & 0.1292 & -0.1644 & 0.8454 & -0.4904 \\
ROE & -0.0567 & 0.0036 & 0.0364 & 0.0478 & -0.0393 & -0.0548 & 0.9851 & 0.0054 & -0.1276 & 0.0437 \\
\hline
\end{tabular}

Thus, the first and the second principal components could be represented as linear combinations out of the original variables, as follows:

- $\quad$ Prin1 $=0.9772 * \mathrm{DE}+0.0255^{*} \mathrm{DTA}+0.1920 * \mathrm{LEV}+(-0.0019) * \mathrm{EPS}+(-0.0225) * \mathrm{PER}+(-0.0003) * \mathrm{ROS}+$ $+(-0.0514) * \mathrm{CR}+(-0.0339) * \mathrm{QR}+(-0.0037) * \mathrm{ROA}+(-0.0567) * \mathrm{ROE}$

- $\quad$ Prin2 $=0.0897 * \mathrm{DE}+(-0.0394) * \mathrm{DTA}+(-0.1369) * \mathrm{LEV}+(-0.0014) * \mathrm{EPS}+(-0.0045) * \mathrm{PER}+$ $+(-0.0029) * \mathrm{ROS}+0.7459^{*} \mathrm{CR}+0.6444 * \mathrm{QR}+0.0062 * \mathrm{ROA}+0.0036 * \mathrm{ROE}$

The financial ratios corresponding to the first ten companies from the sample are showed in Table 5. Therefore, the objects' coordinates in the new space which is constituted, respectively the principal components' scores for the first ten companies are presented in Table 6 being entitled 'Prin1' and 'Prin2'. 
Table 5. Financial ratios for the first ten companies

\begin{tabular}{ccccccccccc}
\hline Company & DE & DTA & LEV & EPS & PER & ROS & CR & QR & ROA & ROE \\
\hline $\mathbf{1}$ & 1.5508 & 0.6079 & 2.5512 & 0.0041 & 0.0779 & 0.0095 & 1.2606 & 0.7506 & 0.0400 & 0.1020 \\
$\mathbf{2}$ & 0.9232 & 0.4800 & 1.9232 & 0.0797 & 0.0242 & 0.8600 & 1.3944 & 1.1457 & 0.2474 & 0.4758 \\
$\mathbf{3}$ & 0.5437 & 0.3522 & 1.5437 & 0.0003 & 0.3649 & 0.0100 & 2.0413 & 1.8580 & 0.0321 & 0.0496 \\
$\mathbf{4}$ & 0.2581 & 0.2052 & 1.2581 & 0.0016 & 0.3393 & 0.0400 & 2.3969 & 2.3341 & 0.0266 & 0.0335 \\
$\mathbf{5}$ & 0.4952 & 0.3309 & 1.4967 & 0.0002 & 0.6569 & 0.0300 & 2.2580 & 1.6246 & 0.0282 & 0.0422 \\
$\mathbf{6}$ & 1.5727 & 0.6113 & 2.5727 & -0.0224 & -0.0284 & -0.0700 & 0.4301 & 0.1483 & -0.0912 & -0.2345 \\
$\mathbf{7}$ & 1.2981 & 0.5273 & 2.4616 & 0.0005 & 0.3167 & 0.0100 & 1.7384 & 0.9651 & 0.0117 & 0.0289 \\
$\mathbf{8}$ & 1.8130 & 0.6010 & 3.0166 & 0.0025 & 0.1742 & 0.0081 & 1.2499 & 0.9884 & 0.0097 & 0.0291 \\
$\mathbf{9}$ & -3.5705 & 1.3890 & -2.5705 & 0.0617 & 0.0046 & 0.2900 & 0.2165 & 0.1638 & 0.0807 & -0.2074 \\
$\mathbf{1 0}$ & 2.0612 & 0.6674 & 3.0886 & 0.0066 & 0.3043 & 0.0100 & 0.3821 & 0.3484 & 0.0332 & 0.1026 \\
\hline
\end{tabular}

Table 6. Principal components' scores matrix

\begin{tabular}{lll}
\hline Company & Prin1 & Prin2 \\
\hline $\mathbf{1}$ & 0.0150 & -1.1199 \\
$\mathbf{2}$ & -0.7636 & -0.7305 \\
$\mathbf{3}$ & -1.2503 & 0.2321 \\
$\mathbf{4}$ & -1.6210 & 0.8234 \\
$\mathbf{5}$ & -1.3167 & 0.2449 \\
$\mathbf{6}$ & 0.1258 & -2.1299 \\
$\mathbf{7}$ & -0.2842 & -0.6341 \\
$\mathbf{8}$ & 0.3550 & -1.0155 \\
$\mathbf{9}$ & -5.8606 & -2.0672 \\
$\mathbf{1 0}$ & 0.6722 & -2.0656 \\
\hline
\end{tabular}

We take into consideration the property that the sum of squares of the coefficients which define the linear combination corresponding to a principal component is equal to one. Thus, the examination of this property by the linear combinations' coefficients which define the principal components, determine the fact that these coefficients under vectorial form compose an orthonormal system.

Thereby, for the first principal component:

$$
\begin{aligned}
& (0.9772|0.0255| 0.1920|-0.0019|-0.0225|-0.0003|-0.0514|-0.0339|-0.0037 \mid-0.0567) \\
& *(0.9772|0.0255| 0.1920|-0.0019|-0.0225|-0.0003|-0.0514|-0.0339|-0.0037 \mid-0.0567)^{t} \\
& =0.9549+0.0007+0.0369+0.0000+0.0005+0.0000+0.0026+0.0011+0.0000+0.0032=1
\end{aligned}
$$

Additionally, for the second principal component:

$$
\begin{aligned}
& (0.0897|-0.0394|-0.1369|-0.0014|-0.0045|-0.0029| 0.7459|0.6444| 0.0062 \mid 0.0036) * \\
& *(0.0897|-0.0394|-0.1369|-0.0014|-0.0045|-0.0029| 0.7459|0.6444| 0.0062 \mid 0.0036)^{t} \\
= & 0.0080+0.0016+0.0187+0.0000+0.0000+0.0000+0.5564+0.4153+0.0000+0.0000=1
\end{aligned}
$$

Figure 2 shows the 310 companies' scores in the first two principal axes plan. We notice a fairly compact group of companies which are inclined to be similarly valued, but also several companies which are detached from the rest of the companies. 


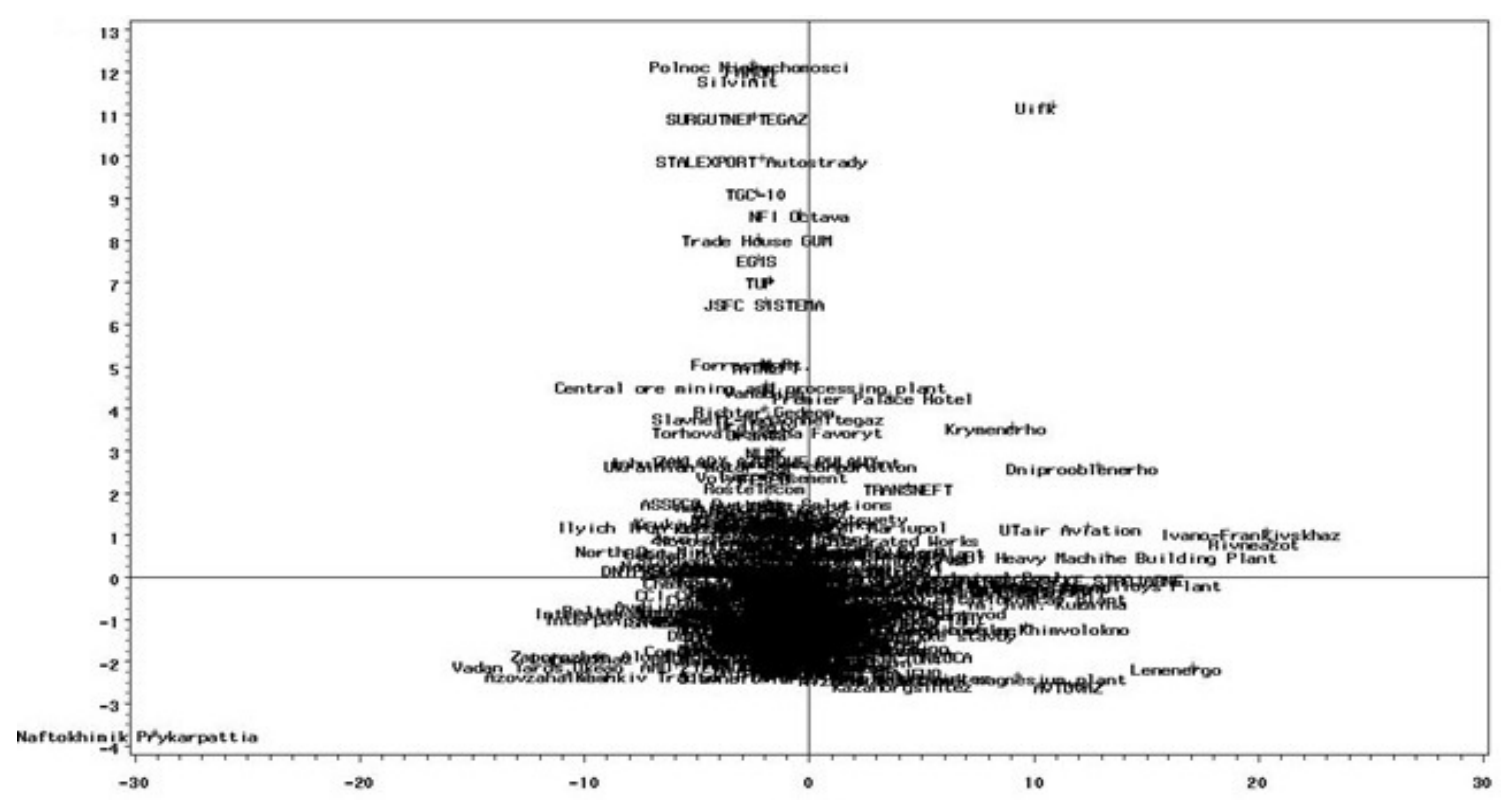

Figure 2. Companies' scores in the first two principal axes plan

The principal components are orthogonal vectors which take as much from the original vector variables' variance as follows: the first principal component take maximum possible out of the original variables' variance, while the second principal component take maximum out of the remained variance after is removed the variance taken by the first principal component.

$$
\begin{gathered}
<\text { Eigenvector } 1 \text {; Eigenvector } 2>= \\
(0.9772|0.0255| 0.1920|-0.0019|-0.0225|-0.0003|-0.0514|-0.0339|-0.0037 \mid-0.0567) \\
*(0.0897|-0.0394|-0.1369|-0.0014|-0.0045|-0.0029| 0.7459|0.6444| 0.0062 \mid 0.0036)^{t}=0.0001 \approx 0
\end{gathered}
$$

From a geometrical point of view, the variables named principal components are defining a new objects' space in the context of which the axes corresponding to the new created space are orthogonal two by two and ascertain the new variables. Moreover, the principal components own a feature which determines their adequacy from the informational point of view in order to substitute the original variables. Thus, this feature refers to the fact that through the principal components is ensured the variability' preservation from the initial causal space. Besides, the diagonal elements of the covariance matrix (Table 1) corresponding to the observations performed to the ten variables are the variances related to the ten original variables, as follows:

$\sigma_{1}{ }^{2}=14.7157, \sigma_{2}{ }^{2}=0.0628, \sigma_{3}{ }^{2}=3.6779, \sigma_{4}{ }^{2}=0.0041, \sigma_{5}{ }^{2}=0.7399, \sigma_{6}{ }^{2}=0.9886, \sigma_{7}{ }^{2}=3.4419, \sigma_{8}{ }^{2}=2.5909$, $\sigma_{9}^{2}=0.0102, \sigma_{10}^{2}=0.1938$

The eigenvalues of the covariance matrix (Table 2) are presented below:

$\lambda_{1}=15.2523, \lambda_{2}=5.8914, \lambda_{3}=3.1881, \lambda_{4}=1.0488, \lambda_{5}=0.6740, \lambda_{6}=0.1772, \lambda_{7}=0.1406, \lambda_{8}=0.0438, \lambda_{9}=$ $0.0065, \lambda_{10}=0.0030$

Thus, the feature previously mentioned is demonstrated as follows:

$\operatorname{tr}(\widehat{\Sigma})=\sigma_{1}{ }^{2}+\sigma_{2}{ }^{2}+\sigma_{3}{ }^{2}+\sigma_{4}{ }^{2}+\sigma_{5}^{2}+\sigma_{6}^{2}+\sigma_{7}^{2}+\sigma_{8}^{2}+\sigma_{9}{ }^{2}+\sigma_{10}{ }^{2}=\mathbf{2 6 . 4 2 5 7}$

$=\lambda_{1}+\lambda_{2}+\lambda_{3}+\lambda_{4}+\lambda_{5}+\lambda_{6}+\lambda_{7}+\lambda_{8}+\lambda_{9}+\lambda_{10}=\operatorname{tr}(\hat{\Lambda})$

Another noteworthy property of the principal components consists in the fact that these are ensuring the whole conservation of the generalized variance corresponding to the original variables. Thus, the determinant of the covariance matrix is equal with the multiplication of the ten eigenvalues, respectively it is equal with the covariance matrix' determinant corresponding to the ten principal components:

$$
\begin{aligned}
|\Sigma| & =0.0000043=15.2523 * 5.8914 * 3.1881 * 1.0488 * 0.6740 * 0.1772 * 0.1406 * 0.0438 * 0.0065 * 0.0030 \\
& =0.0000043=|\Lambda|
\end{aligned}
$$




\subsection{The Results of the Factor Analysis}

The script related to the factor analysis employed in SAS 9.2 is showed in Apendix . The Pearson correlation coefficient matrix related to the original variables is showed in Table 7.

Table 7. Pearson correlation coefficients

\begin{tabular}{lcccccccccc}
\hline Variable & DE & DTA & LEV & EPS & PER & ROS & CR & QR & ROA & ROE \\
\hline DE & 1.0000 & 0.3691 & 0.3039 & -0.1174 & -0.0990 & -0.0031 & -0.0621 & -0.0352 & -0.1366 & -0.5060 \\
DTA & 0.3691 & 1.0000 & 0.2639 & -0.1158 & -0.1416 & 0.0114 & -0.4102 & -0.3915 & -0.3358 & -0.1725 \\
LEV & 0.3039 & 0.2639 & 1.0000 & -0.0207 & -0.0163 & 0.0373 & -0.1044 & -0.1112 & -0.0094 & -0.0727 \\
EPS & -0.1174 & -0.1158 & -0.0207 & 1.0000 & 0.0294 & 0.0870 & -0.0434 & -0.0362 & 0.3783 & 0.1820 \\
PER & -0.0990 & -0.1416 & -0.0163 & 0.0294 & 1.0000 & 0.1614 & 0.0041 & -0.0037 & 0.0471 & 0.0499 \\
ROS & -0.0031 & 0.0114 & 0.0373 & 0.0870 & 0.1614 & 1.0000 & 0.0031 & -0.0070 & 0.2610 & 0.1178 \\
CR & -0.0621 & -0.4102 & -0.1044 & -0.0434 & 0.0041 & 0.0031 & 1.0000 & 0.9395 & 0.1745 & 0.0913 \\
QR & -0.0352 & -0.3915 & -0.1112 & -0.0362 & -0.0037 & -0.0070 & 0.9395 & 1.0000 & 0.1534 & 0.0706 \\
ROA & -0.1366 & -0.3358 & -0.0094 & 0.3783 & 0.0471 & 0.2610 & 0.1745 & 0.1534 & 1.0000 & 0.5106 \\
ROE & -0.5060 & -0.1725 & -0.0727 & 0.1820 & 0.0499 & 0.1178 & 0.0913 & 0.0706 & 0.5106 & 1.0000 \\
\hline
\end{tabular}

The correlation coefficient matrix have a particular importance in order to employ factor analysis because based on the correlations between variables will result a lower number of variables entitled factors. Besides, the factors will explain the variance related to observations.

Table 8 reveals the eigenvalues of the correlation matrix.

Table 8. Eigenvalues of the correlation matrix

\begin{tabular}{ccccc}
\hline & Eigenvalue & Difference & Proportion & Cumulative \\
\hline $\mathbf{1}$ & 2.6342 & 0.8243 & 0.2634 & 0.2634 \\
$\mathbf{2}$ & 1.8099 & 0.5036 & 0.1810 & 0.4444 \\
$\mathbf{3}$ & 1.3063 & 0.2289 & 0.1306 & 0.5750 \\
$\mathbf{4}$ & 1.0774 & 0.1913 & 0.1077 & 0.6828 \\
$\mathbf{5}$ & 0.8861 & 0.0605 & 0.0886 & 0.7714 \\
$\mathbf{6}$ & 0.8256 & 0.2250 & 0.0826 & 0.8540 \\
$\mathbf{7}$ & 0.6006 & 0.0434 & 0.0601 & 0.9140 \\
$\mathbf{8}$ & 0.5572 & 0.3142 & 0.0557 & 0.9697 \\
$\mathbf{9}$ & 0.2431 & 0.1835 & 0.0243 & 0.9940 \\
$\mathbf{1 0}$ & 0.0595 & & 0.0060 & 1.0000 \\
\hline
\end{tabular}

Table 9 shows the factor pattern matrix before rotation, thus being retained two factors.

Table 9. Factor pattern

\begin{tabular}{lcc}
\hline Variable & Factor1 & Factor2 \\
\hline DE & -0.5154 & -0.3850 \\
DTA & -0.7219 & 0.0762 \\
LEV & -0.3332 & -0.0017 \\
EPS & 0.2684 & 0.4714 \\
PER & 0.1510 & 0.1703 \\
ROS & 0.1507 & 0.3085 \\
CR & 0.7029 & -0.6376 \\
QR & 0.6836 & -0.6549 \\
ROA & 0.5952 & 0.4369 \\
ROE & 0.5507 & 0.5322 \\
\hline Variance Explained & 2.6342 & 1.8098 \\
by Each Factor & \\
\hline
\end{tabular}


However, the orthogonal rotation of factors using the Varimax rotation method determined the factor structure showed in Table 10. Besides, the Varimax rotation represents an orthogonal rotation method through which is minimized the number of variables with high loadings on each factor.

Table 10. Rotated factor pattern

\begin{tabular}{|c|c|c|}
\hline Variable & Factor1 & Factor2 \\
\hline DE & -0.1913 & -0.6142 \\
\hline DTA & -0.6292 & -0.3621 \\
\hline LEV & -0.2688 & -0.1969 \\
\hline EPS & -0.0594 & 0.5392 \\
\hline PER & 0.0223 & 0.2265 \\
\hline ROS & -0.0591 & 0.3382 \\
\hline CR & 0.9434 & -0.1036 \\
\hline QR & 0.9378 & -0.1289 \\
\hline ROA & 0.2254 & 0.7031 \\
\hline ROE & 0.1335 & 0.7541 \\
\hline $\begin{array}{l}\text { Variance Explained } \\
\text { by Each Factor }\end{array}$ & 2.3501 & 2.0939 \\
\hline
\end{tabular}

Therefore, this fact simplifies the interpretation of factors. The first factor is compounded mainly of the variables $\mathrm{CR}$ and $\mathrm{QR}$, while the second factor is compounded mainly of the variables ROA and ROE. The first factor explains 23.5 percent out of the variance, while the second factor explains 20.93 percent out of the variance.

Hence, it is obtained the following form of the factor model:

- $\quad$ Factor1 $=-0.1913 *$ DE $-0.6292 *$ DTA $-0.2688^{*}$ LEV $-0.0594 *$ EPS $+0.0223 *$ PER $-0.0591 *$ ROS + $0.9434 * \mathrm{CR}+0.9378 * \mathrm{QR}+0.2254 * \mathrm{ROA}+0.1335 * \mathrm{ROE}$

- $\quad$ Factor2 $=-0.6142 *$ DE $-0.3621 *$ DTA $-0.1969 *$ LEV $+0.5392 *$ EPS $+0.2265 *$ PER $+0.3382 *$ ROS $0.1036^{*} \mathrm{CR}-0.1289 * \mathrm{QR}+0.7031 * \mathrm{ROA}+0.7541 * \mathrm{ROE}$

For the first indicator variable (the debt to equity ratio), the communality is obtained as follows:

$$
\mathrm{h}_{1}^{2}=\mathrm{a}_{11}^{2}+\mathrm{a}_{12}^{2} \rightarrow \mathrm{h}_{1}^{2}=(-0.1913)^{2}+(-0.6142)^{2}=0.0366+0.3772=0.4138
$$

Likewise, for the second indicator variable (the debt to total assets ratio), the communality is obtained as follows:

$$
\mathrm{h}_{2}^{2}=\mathrm{a}_{21}^{2}+\mathrm{a}_{22}^{2} \rightarrow \mathrm{h}_{2}^{2}=(-0.6292)^{2}+(-0.3621)^{2}=0.3959+0.1311=0.5270
$$

The information regarding the specificity was determined by the difference between the variance of each variable and the communality related to both factors.

Thus, for the first measured variable, the specificity is determined as follows:

$$
\mathrm{s}_{1}^{2}=\sigma_{1}^{2}-\mathrm{h}_{1}^{2}=1-0.4138=0.5862
$$

Likewise, for the second measured variable, the specificity is determined as follows:

$$
\mathrm{s}_{2}^{2}=\sigma_{2}^{2}-\mathrm{h}_{2}^{2}=1-0.5270=0.4730
$$

\section{Concluding Remarks}

By employing the principal component analysis in order to evaluate a random sample consisting of 310 companies which belong to five European emerging countries, there resulted the possibility of their evaluation based on two principal components, also considering a minimum loss of information. Thus, by the instrumentality of the first two principal components there is recorded a covering of 80.01 percent of the variability out of the space of the ten selected variables. In fact, the informational loss registered is 20 percent. The utility of the principal component analysis with the aim of companies' valuation is remarkable because there is provided a decomposition of the total variability from the initial causal space expressed through a lower 
number of components. Besides, the decomposition previously mentioned is not redundant. As well, by employing factor analysis there resulted two factors which explain 23.5 percent, respectively 20.93 percent out of the total variance.

However, both principal component analysis and factor analysis have the aim of reduction of the significant number of considered variables. This reduction is made in order to evaluate the selected companies through a lower number of principal components, respectively factors. In case of the principal component analysis the components are identified in order to take as much from the variance existing in the data, whereas in case of the factor analysis the lower number of factors is identified in order to explain why the measured variables are correlated between them.

\section{References}

Abdi, H., \& Williams, L. J. (2010). Principal component analysis. Wiley Interdisciplinary Reviews: Computational Statistics, 2(4), 433-459. http://dx.doi.org/10.1002/wics.101

Ali, H. F., \& Charbaji, A. (1994). Applying Factor Analysis to Financial Ratios of International Commercial Airlines. International Journal of Commerce and Management, 4(1/2), 25-37. http://dx.doi.org/10.1108/eb047285

Alter, O., Brown, P. O., \& Botstein, D. (2000). Singular value decomposition for genome-wide expression data processing and modeling. Proceedings of the National Academy of Sciences of the United States of America, 97(18), 10101-10106. http://dx.doi.org/10.1073/pnas.97.18.10101

Altman, E. I. (1968). Financial ratios, discriminant analysis and the prediction of corporate bankruptcy. The Journal of Finance, 23(4), 589-609. http://dx.doi.org/10.1111/j.1540-6261.1968.tb00843.x

Cattell, R. B. (1966). The scree test for the number of factors. Multivariate Behavioral Research, 1(2), 245-276. http://dx.doi.org/10.1207/s15327906mbr0102_10

Conan, J., \& Holder, M. (1979). Variables explicatives de performances et controle de gestion dans les P.M.I. These d'Etat, CERG, Université Paris Dauphine.

Conway, J. M., \& Huffcutt, A. I. (2003). A review and evaluation of exploratory factor analysis practices in organizational research. Organizational Research Methods, 6(2), 147-168. http://dx.doi.org/10.1177/1094428103251541

De, A., Bandyopadhyay, G., \& Chakraborty, B. N. (2011). Application of the factor analysis on the financialratios and validation of the results by the cluster analysis: An empirical study on the Indian cement industry. Journal of Business Studies Quarterly, 2(3), 13-31.

Delwiche, L. D., \& Slaughter, S. J. (2008). The Little SAS Book: A Primer (4th ed.). SAS Institute.

Dray, S. (2008). On the number of principal components: A test of dimensionality based on measurements of similarity between matrices. Computational Statistics \& Data Analysis, 52(4), 2228-2237. http://dx.doi.org/10.1016/j.csda.2007.07.015

Fabrigar, L. R., Wegener, D. T., MacCallum, R. C., \& Strahan, E. J. (1999). Evaluating the use of exploratory factor analysis in psychological research. Psychological Methods, 4(3), 272-299. http://dx.doi.org/10.1037/1082-989X.4.3.272

Fernandez, G. (2010). Statistical Data Mining Using SAS Applications (2nd ed.). CRC Press.

Ford, J. K., MacCallum, R. C., \& Tait, M. (1986). The application of exploratory factor analysis in applied psychology: A critical review and analysis. Personnel Psychology, 39(2), 291-314. http://dx.doi.org/10.1111/j.1744-6570.1986.tb00583.x

Hancock, P. J., Burton, A. M., \& Bruce, V. (1996). Face processing: Human perception and principal components analysis. Memory \& Cognition, 24(1), 26-40. http://dx.doi.org/10.3758/BF03197270

Hastie, T., Tibshirani, R., Eisen, M. B., Alizadeh, A., Levy, R., Staudt, L., .. \& Brown, P. (2000). 'Gene shaving' as a method for identifying distinct sets of genes with similar expression patterns. Genome Biology, 1(2), 1-21. http://dx.doi.org/10.1186/gb-2000-1-2-research0003

Hastie, T., Tibshirani, R., \& Friedman, J. (2009). The elements of statistical learning. Data mining, inference, and prediction (2nd ed.). Springer Series in Statistics.

Jackson, D. A. (1993). Stopping rules in principal components analysis: A comparison of heuristical and statistical approaches. Ecology, 74(8), 2204-2214. http://dx.doi.org/10.2307/1939574 
Leger, L., \& Leone, V. (2008). Changes in the risk structure of stock returns: Consumer confidence and the dotcom bubble. Review of Financial Economics, 17(3), 228-244. http://dx.doi.org/10.1016/j.rfe.2007.08.001

Meric, G., Leal, R. P. C., Ratner, M., \& Meric, I. (2001). Co-movements of U.S and LatinAmerican equity markets before and after the 1987 crash. International Review of Financial Analysis, 10(3), 219-235. http://dx.doi.org/10.1016/S1057-5219(01)00053-9

O’Toole, A. J., Deffenbacher, K. A., Valentin, D., \& Abdi, H. (1994). Structural aspects of face recognition and the other-race effect. Memory \& Cognition, 22(2), 208-224. http://dx.doi.org/10.3758/BF03208892

Park, H. S., Dailey, R., \& Lemus, D. (2002). The use of exploratory factor analysis and principal components analysis in communication research. Human Communication Research, 28(4), 562-577. http://dx.doi.org/10.1111/j.1468-2958.2002.tb00824.x

Pearson, K. (1901). On lines and planes of closest fit to systems of points in space. Philosophical Magazine, 2(11), 559-572. http://dx.doi.org/10.1080/14786440109462720

Peres-Neto, P. R., Jackson, D. A., \& Somers, K. M. (2005). How many principal components? Stopping rules for determining the number of non-trivial axes revisited. Computational Statistics \& Data Analysis, 49(4), 974-997. http://dx.doi.org/10.1016/j.csda.2004.06.015

Pinches, G. E., Mingo, K. A., \& Caruthers, J. K. (1972). The stability of financial patterns in industrial $\begin{array}{lllll}\text { organizations. The Journal of } & \text { 389-396. }\end{array}$ http://dx.doi.org/10.1111/j.1540-6261.1973.tb01782.x

Tan, P. M. S., Koh, H. C., \& Low, L. C. (1997). Stability of financial ratios: A study of listed companies in Singapore. Asian Review of Accounting, 5(1), 19-39. http://dx.doi.org/10.1108/eb060680

Thurstone, L. L. (1931). Multiple factor analysis. Psychological Review, 38(5), 406-427. http://dx.doi.org/10.1037/h0069792

Zou, H., Hastie, T., \& Tibshirani, R. (2006). Sparse principal component analysis. Journal of Computational and Graphical Statistics, 15(2), 265-286. http://dx.doi.org/10.1198/106186006X113430 


\section{Apendix 1}

Principal component analysis script employed in SAS 9.2

PROC IMPORT DATAFILE = 'E: $\backslash$ SAS $\backslash$ Database. $x l s '$ out = companies replace;

getnames = yes;

RUN;

PROC PRINT DATA = companies;

ID company;

RUN;

PROC SORT data = companies;

by company;

RUN;

ods html;

ods graphics on;

PROC CORR data $=$ companies outp $=$ out 1 ;

var DE DTA LEV EPS PER ROS CR QR ROA ROE;

RUN;

PROC PRINCOMP data $=$ companies cov out $=$ Ratings $\mathrm{n}=\mathbf{1 0}$ outstat $=$ pca_results;

var DE DTA LEV EPS PER ROS CR QR ROA ROE;

title 'PCA Results';

RUN;

PROC PLOT data = Ratings;

plot prin $2 *$ prin $1=$ '+' \$ company;

RUN;

DATA ratings_hq;

set ratings;

$\mathrm{x}=\operatorname{prin} 1$;

$y=\operatorname{prin} 2$;

text $=$ company;

size $=\mathbf{1}$;

xsys $=$ ' 2 ';

ysys $=$ ' 2 ';

label $\mathrm{x}=$ 'axis 1 ';

label $\mathrm{y}=$ 'axis 2 ';

keep x y xsys ysys text size;

RUN;

title 'The first two principal components area';

PROC GPLOT data = ratings_hq;

plot $\mathrm{y}^{*} \mathrm{x}=\mathbf{1} /$ annotate $=$ ratings_hq href $=\mathbf{0}$ vref $=\mathbf{0}$;

RUN;

QUIT;

title 'Ratings matrix';

PROC PRINT data = ratings;

RUN;

title 'PCA Statistics';

PROC PRINT data = rez_ACP;

RUN;

ods graphics off;

ods html close;

\section{Apendix 2}

\section{Factor analysis script employed in SAS 9.2}

PROC IMPORT DATAFILE = 'E: $\backslash$ SAS $\backslash$ Database. $x l s '$ out = companies replace;

getnames = yes;

RUN;

ods html; 
ods graphics on;

PROC FACTOR data $=$ companies $\operatorname{method}=$ principal scree mineigen $=\mathbf{0}$ score priors $=$ smc;

outstat $=$ facto_results;

var DE DTA LEV EPS PER ROS CR QR ROA ROE;

RUN;

PROC FACTOR data $=$ facto_results $\operatorname{method}=$ principal $n=\mathbf{2}$ rotate $=$ varimax score outstat $=$ facto_results_2f;

RUN;

PROC SCORE data $=$ companies score $=$ facto_results_2f out $=$ ratings;

RUN;

PROC PLOT;

plot factor $2 *$ factor 1 ;

RUN;

ods graphics off;

ods html close;

\section{Copyrights}

Copyright for this article is retained by the author(s), with first publication rights granted to the journal.

This is an open-access article distributed under the terms and conditions of the Creative Commons Attribution license (http://creativecommons.org/licenses/by/3.0/). 